$5-1-2013$

\title{
Democracy and Scientific Expertise: Illusions of Political and Epistemic Inclusion
}

\author{
J.D. Trout \\ Loyola University Chicago, jtrout@luc.edu
}

Follow this and additional works at: https://ecommons.luc.edu/philosophy_facpubs

Part of the Ethics and Political Philosophy Commons

\section{Author Manuscript}

This is a pre-publication author manuscript of the final, published article.

\section{Recommended Citation}

Trout, J.D.. Democracy and Scientific Expertise: Illusions of Political and Epistemic Inclusion. Synthese, 190, 7: , 2013. Retrieved from Loyola eCommons, Philosophy: Faculty Publications and Other Works, http://dx.doi.org/10.1007/s11229-012-0226-4

This Article is brought to you for free and open access by the Faculty Publications and Other Works by Department at Loyola eCommons. It has been accepted for inclusion in Philosophy: Faculty Publications and Other Works by an authorized administrator of Loyola eCommons. For more information, please contact ecommons@luc.edu. c) (i) $(9$

This work is licensed under a Creative Commons Attribution-Noncommercial-No Derivative Works 3.0 License. (C) 2013 Springer. 
Democracy and Scientific Expertise: Illusions of Political and Epistemic Inclusion ${ }^{1}$

\author{
J.D. Trout \\ Department of Philosophy and Psychology \\ Loyola University Chicago \\ www.jdtrout.com \\ jtrout@luc.edu
}

Realizing the ideal of democracy requires political inclusion for citizens. A legitimate democracy must give citizens the opportunity to express their attitudes about the relative attractions of different policies, and access to political mechanisms through which they can be counted and heard. The most influential expression of these objectives derives from the political philosophy underlying democratic theory. Robert Dahl, the celebrated political scientist, describes political inclusion as a guiding principle of democratic decision-making: "When binding decisions are made, the claims of each citizen as to the desirability of the policies to be adopted must be counted as valid and equally valid." ${ }^{2}$ Put another way: "Throughout the process of making binding decisions, citizens ought to have an adequate opportunity, and an equal opportunity, for expressing their preferences as to the final outcome." ${ }^{3}$

Of course, gross inequalities exist in all democracies, and this often foments unrest. To quiet turmoil over inequalities, Dahl points out, it may be enough to simply make people "feel” heard: "When demands for greater equality do arise, a regime may gain allegiance among the deprived groups by responding to some part of the demands, though not necessarily all of them, or by responses that do not reduce the objective inequalities but do reduce feelings of relative deprivation." ${ }^{4}$

However insufficient procedural rules may be in securing substantive justice, people can rationally support procedural standards for purely instrumental reasons. A procedure that regularly fails to produce a fair outcome may nevertheless be worth supporting because it is better than other options. 
As Dahl puts the point: "Although that process cannot guarantee that all the members will literally live under laws of their own choosing, it expands self-determination to its maximum feasible limits. Even when you are among the outvoted members whose preferred option is rejected by the majority of your fellow citizens, you may nonetheless decide that the process is fairer than any other that you can reasonably hope to achieve. To that extent you are exercising your freedom of self-determination by freely choosing to live under a democratic constitution rather than a nondemocratic alternative." ${ }^{5}$

A key part of political inclusion is epistemic inclusion, which is the provision that individuals should have access to knowledge and the effective opportunity for that knowledge to influence both their political decision making and political outcomes. Democratic constitutions carefully craft procedures that allow citizens to express their political will, but that expression is autonomous and dignified only when it is informed and effective. Information and knowledge is a crucial feature of responsible self-governance, and it is in this way that epistemic and political inclusion makes theoretical contact.

Of course, a great distance separates the airy climes of academic epistemology and the gritty practical knowledge of politics, but the connection is also undeniable. What, then, is the supposed connection between epistemic accuracy and inclusion? Indeed, there is a gratifying Enlightenment vision that sustains this connection in most academic epistemology. It assumes that individuals have an interest in basing their decisions on sound information, and that pursuing this information is the responsibility of the decision-making agent. ${ }^{6}$ If you identify the goals of a voting body, reaching those goals will be better served by political decisions that are more rather than less likely to be true. And the truth of your beliefs is non-accidentally related to the quality of your evidence.

What is the relation between the epistemic norm that decisions ought to be made in light of the best available evidence, and the significance of epistemic inclusion, either of diverse viewpoints or of viewpoints of interested parties, in different kinds of decision-making? The more accurately a 
procedure portrays the full range of human values and interests, the more likely any given person's values will be expressed. So having the best available evidence is, in more than one way, a key value in political decision-making.

It is certainly possible that allowing interested parties the opportunity to express their views (epistemic inclusion) is unrelated to making political decisions reliant on the best available evidence. But this connection has been accepted, as a descriptive matter of fact, ever since the Enlightenment. Of course, it might be a mistake to allow inexpert individuals the opportunity to express their views about arcane matters of science - the chief topic of this paper. But inexpert individuals can sensibly decide what sort of procedure they would want to implement in order to achieve their desired ends.

There is a straightforward reason we should expect a connection between epistemic inclusion and quality of evidence. In a population with a plurality of values, it is more likely that you will accurately capture the full range of values of citizens' interests if political procedures reflect citizen preferences. Now, it may be that each citizen may not always know what is in their own interest indeed, our best scientific psychology could be used to determine it better, or to predict when individual judgment about one’s own preferences will fail. After all, people often have unrealistic goals, unduly optimistic assessments of their own skills, and systematically inaccurate predictions about what future states they will prefer. These cognitive deficiencies are core findings of contemporary research in judgment and decision-making. ${ }^{7}$

It is true that citizens in a free society also place a value on self-determination and owning their own mistakes. At the same time, while we claim this as a right, it is not unqualified. We cannot pursue our own good if it violates the rights of others. Qualified as well is the value of owning our own mistakes. It is not clear why inexpert citizens should be permitted the charade of responsible judgment about technical matters; indeed, protecting the value of self-expression in these technical matters seems to not only valorize ignorance, but institutionalize a patronizing attitude toward citizen judgment. 
(Imagine a policy expert observing citizens who are struggling with literature on the safe disposal of nuclear waste, and saying to a cohort, “They don’t understand what radiation is, or a karst environment, but it is important that they try.”) Citizens in a democratic society should value self-determination, and expect dignified rather than condescending treatment from our policy-making Representatives, but we should not permit the conceit of deciding arcane matters ourselves.

Instead, we should engage in the familiar process of deference. We defer to plumbers, mechanics, engineers, and electricians. We defer to doctors and lawyers. In those cases we choose to do so because we appreciate the fact that they know more about the relevant subject matter. The same is true of technical matters in science. But this recognition does not amount to voluntary exclusion, because the ordinary citizen can certainly vote for procedures or for proxy individuals by which to make arcane decisions. In doing so, they are sill exerting their will about the procedure to supplant their inexpert judgment.

It is not that an epistocracy (the form of government in which rule is given to those who hold the most (political) wisdom ${ }^{8}$ ) is necessarily illegitimate, letting those with the most relevant knowledge lead. But to effectively govern, political knowers must also recognize how pieces of knowledge are to be weighted - how much each issue matters to various groups of people. The point is rather that the open discussion of citizen views - including procedural guarantees of effective avenues of influence is the most efficient and straightforward way to represent citizens' views and priorities.

Of course, one could always concoct an overall measure by which an epistocracy tracks and perhaps even surpasses the effectiveness, representativeness, and the feeling of satisfaction in citizens that it produces. But it is equally clear that in order to do so we would need to know much more than we do now about the actual requirements of well-being. ${ }^{9}$ On my view, inclusiveness is important not because it is necessarily the golden road to truth, but that it can be the best alternative when the 
evidence is not theoretically arcane. Given this, the best way to achieve the epistemic ends of politics is to actually include people in the decision-making process.

While a representative committee's use of informed and reliable methods of decision-making does not mean that the citizenry is "included," still less "autonomous”, it is the most direct way that you as a citizen can hope to exercise your will in the political process on issues you can't vote on yourself. The relations between judgment and policy are seldom logical or causal entailments. So you look for probabilistic relations that might be underwritten causally. When I vote for political representatives, I do so because I want them to - and believe they will - represent my interests. If they fail to represent my interests, I want it to be because they have considered all of the relevant evidence and disagree, and not because, as I will show is often the case later, they ignored the best available evidence and voted (for undisclosed reasons) for the interests of their nontransparent donors.

With these qualifications in place, we can advance a modest epistemic principle worth defending in contexts of practical policy. Many different epistemological positions and approaches to justification - foundationalist, contextualist, and reliablist, for example - rely on the notion that epistemic agents have a responsibility to educate themselves about the quality of evidence for their beliefs. In fact, there is a generic principle of epistemic responsibility that they all share:

Generic Epistemic Principle: Whatever the procedures used, they should be selectively sensitive to the evidence. ${ }^{10}$

At first glance, this generic epistemic principle looks utterly uncontroversial. And on a second, closer inspection, it continues to look this way. Who could possibly object to the idea that we should be preferentially responsive to the highest-quality evidence? After all, what would an opposing position 
be? That we should be uniquely attracted to suboptimal evidence? Or focusing on the method, should we adopt procedures that are insensitive to the best available evidence?

It is true that the principle that policy choices ought to be made in light of the best available relevant evidence does not simply fall out of all epistemological views, but at a minimum it does fall out of a prominent form of epistemic naturalism. ${ }^{11}$ More generally, it seems to be behind a general Enlightenment idea that science not only gives us truth but clears the path to liberty. Science received this elevated treatment because it was seen as a method uniquely capable of delivering knowledge, including knowledge about our own limitations. ${ }^{12}$ So, in the late $18^{\text {th }}$ century, part of that process was to educate oneself about the scientific evidence bearing on self-governance. This was certainly Hume’s expectation when he wrote that:

"Where experiments [from cautious observations of human life] are judiciously collected and compared, we may hope to establish on them a science, which will not be inferior in certainty, and will be much superior in utility to any other of human comprehension."13

This sentiment was not restricted to the Scottish Enlightenment. Diderot offers up the philosopher as the model of a rational decision-maker. But this philosopher has an Enlightenment style of reasoning: “...who, trampling underfoot prejudice, tradition, venerability, universal assent, authority - in a word, everything that overawes the crowd - dares to think for himself, to ascend to the clearest general principles, to examine them, to discuss them, to admit nothing save on the testimony of his own reason and experience.”14 But, of course, these Enlightenment views do not require that the knowing agent is alone in the world. Part of the testimony of one's own reason and experience may be that in 
technical matters one would be wise to defer to experts. But you would follow this advice only if you thought that, in general and in the long run, truth is a better guide to action than falsehood.

While some philosophers worry that there is no connection between good judgment and inclusiveness, and so the Generic Epistemic Principle is too strong, others worry it is too weak. On this view, a principle is hardly action-guiding if it is so thin - so completely unobjectionable - that violating it counts as a pathology. ${ }^{15}$ And yet, in practice there are many law-making bodies of the U.S. Government that routinely flout this humble principle. For example, there are 23 committees in the House of Representatives that forge policies and make law: House Committees on Agriculture, Budget, Ethics, Financial Services, Homeland Security, Judiciary, Ways and Means, and many more. The members of these committees make their decisions in a group setting - after the committee hosts panels of experts to consult on the relevant issues, followed by sessions to discuss them with one another. Despite all of the scientific evidence about the systemic cognitive biases that cripple individual judgment and group decisions, these committees, as a matter of procedure, ignore scientific evidence, and allow members to engage in campaigns of partisan misrepresentation that, once again, violates the Generic Epistemic Principle. At the same time, the committee offices maintain procedures that, like kabuki theatre, create an appearance of expertise.

I will argue that the routine procedures in practical governance and policy making suffer from two failures at once: They are insensitive to the best available evidence, and they are selectively responsive to demonstrably suboptimal evidence. Because this makes political procedures vulnerable to the most corrupt nonepistemic influences, they are profoundly truth-distorting. In what follows, I want to document the kinds of clear scientific evidence legislators have to ignore in order to participate in these sham procedures. Using an elaborate illustration of apparent scientific dishonesty and negligence in the U.S. House Committee on Science, Space, and Technology ${ }^{16}$ - a body that should use sciencebased decision-procedures if anybody does - I will close with a number of positive procedural 
proposals designed to reduce or eliminate these violations of the Generic Epistemic Principle. Along the way, I will allude to the many ways that mega-democracy in the U.S. appears to address public concerns and provide citizen access to the channels of information when no such responsiveness is permitted. $^{17}$

\section{Individual and Group Decision-Making}

When it comes to using science to improve governmental decision-making, there are practical barriers everywhere. At the individual level, humans suffer from a wide range of crippling biases, many of them arising from our individual cognitive limitations. We have severe limits on memory that force us to resort to mental shortcuts of questionable reliability. When we can't get or process the accurate frequency information about dangers in our environment, we rely on cues of psychological salience as a guide to identifying significant threats. But psychological salience marks perceived threats, some of which are not genuine. We are chronically overconfident, content with hindsight, and tyrannized by the psychological inertia induced by existing options. All of these barriers prevent us from participating effectively in advancing our own interests. But on this topic, there is at least this much hope: If you know your limitations, you may at least have an opportunity to formulate methods to surmount them. And we now have a battery of weapons in the war on poor individual and group judgment.

Where did these weapons come from? There is a simple view - one that comes from a philosophical naturalism - that predicts that the theory of knowledge will find its final resting place in a completed cognitive science. Most probably, it will settle into a branch of cognitive science that investigates good reasoning. This field includes work in psychology, statistics, machine learning and Artificial Intelligence. Some of this work involves "predictive modeling” and includes highly technical discussion of such things as linear models, multiple regression formulas, neural networks, naïve Bayes 
classifiers, Markov Chain Monte Carlo algorithms, decision tree models and support vector machines. Yet much of this work also comes from traditional psychology, and includes the well-known heuristics and biases program launched by Kahneman and Tversky. ${ }^{18}$ This wide-ranging literature has been called Ameliorative Psychology. Ameliorative Psychology’s essential feature is its aim to give positive advice about how we can reason better.

An example of Ameliorative Psychology making evaluative ought-claims is a 1995 paper by Gigerenzer and Hoffrage entitled, “How to Improve Bayesian Reasoning Without Instruction: Frequency Formats” (emphasis added). As the title of the paper suggests, Gigerenzer and Hoffrage show how people charged with making high-stakes diagnoses (e.g., about cancer or HIV) can improve their reasoning through strategies that enhances reasoners' ability to identify, on the basis of medical tests, the likelihood that an individual will have cancer or HIV. For now, it is enough to note that a finding of Ameliorative Psychology is that people ought to use frequency formats when diagnosing rare conditions on the basis of well-understood diagnostic tests. ${ }^{19}$

Another particularly successful example of Ameliorative Psychology is credit scoring. Many financial institutions no longer rely primarily on financial officers to make credit decisions - they now make credit decisions on the basis of simple statistical prediction rules (SPRs) developed as the result of research by psychologists and statisticians. ${ }^{20}$ Once again, this finding of Ameliorative Psychology seems to be normative through and through: When it comes to making predictions about someone's creditworthiness, one ought to use a credit scoring model.

The list goes on and on. Predictive models or SPRs outperform subjective or intuitive judgment for decisions that affect millions of people every year. SPRs more accurately predict success of electroshock therapy, criminal recidivism, academic performance, the presence of progressive brain dysfunction, the location and cause of brain damage, proneness to violence, and even the vintage of a wine. And these procedures typically achieve higher accuracy at lower cost. ${ }^{21}$ 
Our best scientific evidence shows how to avoid documented decision traps, and embrace improved decision structures. Developments such as these are important here because better governance lies with better decision-making. This connection between science and governance has a long history. Once we have knowledge about the requirements of well-being, and we can meet those requirements in a way that doesn't make others significantly worse off, we may have moral reasons to perform actions that make us epistemically better off and fulfill our potential well-being. ${ }^{22}$

We are routinely unaware of these cognitive limitations, and this condition renders citizens ineffectual and excluded from the process of governance. But why should we care about inclusiveness anyway?

The short answer is that we do not suppose that a person is being treated with dignity unless their behavior is truly autonomous, undistorted by ignorance, deception, etc. As well, their efforts are without dignity if there is not a reasonable chance to succeed. Once we know that there is a bundle of psychological techniques that make objectively marginalized and powerless citizens mistakenly feel respected and heard, then citizens, scientists, and policy-makers should devise decision structures to expose these deceptions and punish them when encountered. While people want to feel included and heard, the goal isn't just to find the ways to make epistemic actors or citizens feel heard. At least as important as feeling heard is actually being heard. But more than that, even if there are people trained in predictive modeling or individual and group decision-making, they could only act as advisors; we wouldn’t want to substitute our own judgment with theirs. Put another way, you can't really have individual experts routinely make decisions that substitute for a consensus. People necessarily have to act in groups, and they want to feel that they have been listened to. That is one of the key findings of psychological work on procedural justice and legitimacy. 
The social psychologist Tom Tyler has done influential work on the policies, procedures, and social behaviors that make citizens feel "heard” or "listened to", and so incline them to report a procedure or policy as legitimate. ${ }^{23}$ These approving reports turn up even when the policy conflicts with the citizen's expressed interest, or when authority over them is abused. So, unless advocates of evidence-based policy want psychological research to be used as a how-to manual for extracting compliance from unwitting or mistreated citizens, they should focus attention on more objective measures of citizen well-being, and on the importance of citizens' believing true things about themselves and others.

Most standards for reliable or otherwise fit belief formation are individualistic. In light of the voluminous work on the routine foibles of human judgment, there are prominent models of decisionmaking, often group decision-making, designed to produce better decisions and to capture the special impact of epistemic inclusiveness. The best practical example is the citizen panel or minipublic, in which a stratified sample of citizens is selected to learn about, discuss, deliberate about, and then vote on a technical civic issue. Citizen panels are used in Canada and Europe to discuss and create policy. In 2004, a Citizens’ Assembly in British Columbia gathered 160 randomly selected citizens, held 50 public hearings, and worked together for more than 10 months, charged with proposing a new referendum system for the province. ${ }^{24}$ Now here is the interesting twist, for those interested in the connection between epistemic standards and citizen inclusion: The provincial government guaranteed that the recommendation of the Citizens’ Assembly would appear on the ballot as a referendum proposal, and the vote on it would be binding on the current political institutions. It was the first time a representative subset of ordinary citizens had been empowered to propose basic changes to a democratic country’s political institutions, to be decided upon in a general or local election.

There are, however, more abstract and formal models of the relationship between inclusiveness and accuracy. People ordinarily suppose that, when it comes to reasoning, groups are the sum of their 
parts. If some group reached a solution to a problem that faced all members, this fact could always be explained by appeal to the performance of each person in the group. This primitive idea of aggregation gets its fullest expression in Condorcet's jury theorem. In its simplest form, Condorcet's theorem says that if a jury is facing a binary choice, and each jury member makes her decision independently with a better-than-even chance of making the right decision, then a simple majority of the jurors are likely to make the right decision. This procedure will tend toward certainty as the number of jurors tends towards infinity.

A less transparent example of another aggregative approach is recounted by James Surowiecki in The Wisdom of Crowds. The great $19^{\text {th }}$ century statistician Francis Galton turns a local fair into a test of a model of the average voter. At the fair, about 800 people were asked the weight of a particular ox after it was slaughtered and dressed. The average prediction was 1197 . The ultimate weight, as it happens, was 1198. Now, Galton had his own reasons for testing the power of group decision-making; he thought that average of a mixed vote was every bit as incompetent as he believed the great unwashed to be, and he fully hoped the results would show the importance of good breeding.

There is no consensus about the similarity between Galton's case and Condorcet's theorem. But they are both aggregative in the sense that the prediction (of the outcome) grows in accuracy as the number of independent observations increases. Sometimes, it seems, you can just run with a summary of decisions made independently. But in most group settings, the assumption of independence is violation. In groups, people share information and decide together. So you should expect unstructured group decision-making to produce outcomes different from those in which you simply aggregate individual decisions.

Given the success of predictive models, Paul Meehl has said, "In most practical situations an unweighted sum of a small number of 'big' variables will, on the average, be preferable to regression equations.”25 Dawes and Corrigan succinctly state the cash value of these results: To be more reliable 
than expert humans in the social arena, "the whole trick is to know what variables to look at and then know how to add."26

So, these simple questions have relatively simple answers. First, linear models that are superior to human judgment can succeed using a small number of variables because in the systems to which they apply, just a handful of variables account for the vast majority of the model's performance, and the rest only tiny increments. Second, these models outperform humans because humans rely on a greater number of nondiagnostic cues; the process of constructing the linear model is designed to isolate the variables that are most predictive of the desired outcome.

\section{$\underline{\text { Psychological Models of Group Deliberation }}$}

When people deliberate in groups, their decisions are the result of interaction rather than mere aggregation of decisions arrived at independently. And because of this interaction, group decisionmaking is prone to another set of distortions, known as group polarization. The first demonstration of group polarization was by Stoner in 1961 (so it has been known for a long time ${ }^{27}$ ), and following Stoner's work there were many early studies, with the effects being easy to describe.

In one study of policy decision-making, Cass Sunstein and his colleagues assembled citizens in Colorado for group deliberation. In Boulder, a group of liberals came together to discuss politics among themselves for a day. In Colorado Springs, a group of conservatives did the same. The predicted effect emerged: The liberals became more liberal, the conservatives more conservative. Diversity was smothered, while extremism thrived. The same thing happened in his study on judges. When a threejudge panel comprised only Republican appointees, their thinking became extremely right-wing, as did a similarly appointed three-judge Democratic panel. The solution is to expose oneself to competing viewpoints: If you want to avoid group polarization effects, you should spend more time with people you disagree with. ${ }^{28}$ 
This behavior has the broad contours of “Groupthink” phenomena, suppressing dissenting opinions and cultivating a false consensus. We know a lot about how to characterize these behaviors. They are not simple, but they are stable. First, under the forces of group polarization, decisions are influenced in the direction of the position endorsed by the largest number of people. But this is different from the mean judgment. The effect is really a kind of artifact of normative social influence the fact that the mean individual position is just one of many ways of measuring and predicting what the group will do. ${ }^{29}$ Second, we are more influenced by certain other people, like those upon whom we are trying to make a good impression ${ }^{30}$ or those with whom we identify. ${ }^{31}$ The third explanation applies to cases in which group discussion is on a topic with a correct answer (like math, as opposed to a value judgment). Where arriving at truth is assigned high value, then the most logical argument will have the most influence. In this "truth wins" version of the social decision scheme, if there is a single group member who explains the correct answer, everyone else will go along. So in group decision-making, people should be aware that information can be socially influential. And when those influences are not truth-conducive, we should try to blunt or reverse their impact.

In addition to group-psychological influences, existing political structures can also be obstacles to accurate decision-making. Consider, for example, the effect of lobbying influences or the quiet and persistent support of political organizations through bottomless war chests. Regarding these practices in our democracy, it is hard to imagine someone saying "Here's a great way to serve the interests of our citizens and the search for truth in a democracy: Make campaigns for political offices prohibitively expensive for ordinary citizens. Instead, practically restrict running for political office to the independently wealthy and/or those who seek and accept lobbying money from influential companies and industries with a decided interest in specific legislation.” No normative perspective would count this process as a reliable recipe for finding the truth or representing the public. But it is an excellent way for individuals and business with lots of money to capture the legislative process. If left 
unchecked, it will bend legislation to the will of business, industry, inherited or acquired wealth independent of the interests of $90 \%$ of the U.S. population.

One of the great non-stories among psychologists is that people’s attitudes, choices and decisions can be shaped guided in surreptitious ways. Produce cognitive dissonance and you will improve a person's attitude toward an unpleasant task. Create a schedule of random negative reinforcement and you will keep people anxious. They won't know why, and may not recognize the effect, but experts who design the schedule can. And few are surprised by this observation about politics in our megademocracy. People may be able to appreciate that our choices can be shaped by nonepistemic interests, but unable to notice, let alone reverse, the effect. So it should not be surprising that great injustices can be done to people in a way that leaves them feeling that they have been treated justly. In fact, framing research shows how to present options in a way that people will accept when they otherwise wouldn't.

Hear an expression like “deep sea energy exploration” and it feels unfair to argue against it. Who could oppose offshore energy exploration? Well, you might if the energy is oil, the goal is not exploratory learning but corporate expansion, and it involved drilling. Priming research in psychology has shown that language processing is a dynamic whirring of concept activation and inhibition. ${ }^{32}$ Any content word like, say, 'oil' will spread measureable activation to other associated concepts, like 'spill', or 'scandal' or 'Exxon Valdez' or 'BP'. The word 'energy', on the other hand, is more uniformly associated with something good - 'electricity', 'vibrant', and so on. So, there is a great premium on selecting words that replace those with negative implications by ones that prime positive frames. Of course, if you are choosing your words to deliberately suppress negative frames that nevertheless accurately capture the activity's risks and potential consequences, perhaps those words are selected to mislead. Calling inheritance tax “death taxes” seems misleading because only inheritors are getting taxed, and they are very much alive. Indeed, dead people don't have legal standing, and thus cannot 
truly have taxes levied against them. What's more, that expression obscures the fact that people who oppose inheritance tax associate themselves with the doctrine that only people who work hard and contribute to an outcome deserve the proceeds and yet, inheritors seldom apply effort or contribute. So, the very people who oppose inheritance tax should be most offended by its idle acquisition. Yet, the expression "death taxes" shifts focus toward the lost life of the person who once owned the wealth, and away from the idle beneficiaries of that wealth. Or take another example: Calling school vouchers “opportunity scholarships” when they would provide an opportunity only to those who have the resources to use them, or the luck to receive them. But if their use in private schools undermines public funding for schools, they defeat opportunities for others and do not indicate academic distinction ordinarily associated with the term “scholarship.” The point here is not to provoke partisan quibbling. Instead, it illustrates just one way that people in a political process can select vocabulary that predictably misleads.

Citizens have a responsibility to be dutiful agents, and part of that involves knowing the issues of the day. We expect people to know who is running for election, the candidates' respective platforms, and what we think about that slate of issues. But just as important is what we don't expect people to know. We don't expect people to know things that are kept from them, hidden, or buried in a mountain of detail. We also don't expect people to know the arcane details of technical legislation. One reason we don't expect citizens to know the special features of stem cells or the special dangers of plastics is that we do not believe that citizenship should not be a full time job, especially when it turns out governance itself isn't. ${ }^{33}$ And while adequate mastery of these topics would require if not a degree at least a series of well-designed seminars, that demand is simply incompatible with those on us in other equally important areas of our lives. We are, after all, not just citizens but also parents, friends, employees, homemakers, commuters, mortgage holders, community volunteers, underemployed professionals, unemployed laborers, schoolteachers, and so on. It is impossible to give these activities 
the attention they deserve and inform ourselves at expert levels on every single political issue of the day.

Because of this, the majority of U.S. citizens - and probably citizens of large democracies everywhere - are excluded from large portions of the political process. This is a special kind of exclusion. It is not the principled, formal kind of exclusion suffered by subjects under monarchies, oligarchies and tyrannies. Under Ramses I, Pericles, Claudius, Charlemagne, Otto II, Hitler, Stalin, and Mao, the government benefitted from the work or slaves and serfs, but denied them all benefits of citizenship because of their social position. Exclusion of this sort is now universally deplored because it denies people autonomy, because there are no formal mechanisms through which they can express their desires or political will. ${ }^{34}$ This exclusion is principled or formal because, even if people could adequately inform themselves about issues of the day, they could not use this information to improve their situation or change the situations of others.

In fact, history is dominated by illegitimate governments, some of them leading to the present. Military dictatorships, inherited thrones, and organized oligarchy all deny their publics a measure of control over each citizen's life that would amount to dignity. Yet, we often feel that an authority is legitimate when it isn’t. Millions of people acquiesce in, even embrace, the commands of politically illegitimate powers. Some world leaders, beloved by their subjects, ascended to their positions by something like the divine right of Kings. Some would not have held their jobs without their fathers before them. Resting as it does on non-epistemic factors, each of their stations falls short of the ideal of legitimacy.

Virtual Legitimacy Leads to Virtual Inclusion. 
Social psychologist Tom Tyler turned Robert Dahl’s suspicion into a demonstrated fact of life in a megademocracy. Tyler shows that ordinary folks care about procedures, and not just to the extent that those procedures bring good outcomes for you. They care even when those procedures bring bad outcomes for you. This has to do with how you feel you are being regarded by others. Are others considering your views, are they "hearing” you, are you treated as though your view matters, and that the expression of your view could influence a decision or the outcome (whether or not it does)?

Tyler's research provides a ready recipe for ersatz justice. A procedure or outcome is virtually legitimate when it feels legitimate whether or not it is. And when citizens have this feeling whether or not their participation leads to a substantial outcome, they experience fig leaf justice, an illusion of inclusion.

Politicians may enjoy the lunge and parry of debate, and even the dance of ideas, but ultimately what they generally want (in addition to re-election) is compliance; they want citizens to accept the policy decisions of their political representatives. The interest in truth, then, may be transformed into the pragmatic one of creating conditions that establish compliance. And, commenting on his own research, Tom Tyler notes that "people are more willing to accept decisions when they feel that those decisions are made through decision-making procedures they view as fair.”35

But doesn’t that set the justice standard sadly low? Once politicians know that procedures alone can induce this feeling of legitimacy, doesn't it remove the incentive to pursue the genuine article when an equally valuable substitute - like a citizen's vote - could be secured at half-price? In the same way that mannequins can be life-like without being alive, some outcomes can be justice-like without being just. And justice-like psychological impressions can be manufactured at will. In every political system, there are ways that people are made to feel heard even when the substance of what they say is not just ignored, but actively extruded through political procedures that make it impossible to listen to, and act on, what is being said. 
These methods have an interesting property in common: They are designed to make people feel valued even as they are being neglected. These tactics don't make any of the moves you might if you actually valued the people in question - no severance package, and no commitment to hire them back when the company expands again. The tactics are designed to spin the undignified task of firing people for nothing they've done, but to do so without any costly aftertaste. One way to make people feel that decisions are being made fairly is to actually make them fairly (this may require that you do so in a way that make the fairness of the process transparent so that people will also feel it is fair). But another way is to manipulate an unfair procedure just enough to make people feel like decisions are being made fairly. When evaluating whether a process is fair, people look for a few features: Are there opportunities for people to participate in the process, are the authorities in the process neutral, do we trust the motives of those authorities, and are people treated with dignity and respect during the process?

There is nothing sinister in the research discussed above, of course. The researchers responsible for the focus on ersatz justice never say that the feeling of justice experienced from procedures designed to provoke those feelings provide the genuine article, any more than they say that the feeling that your laws are legitimate means that they are. The main worry, instead, is that this distinction is not addressed, or actual legitimacy is beyond study because it can't be operationalized. While that is unlikely, studying it would require a wealth of tools and approaches from different disciplines. But even if real legitimacy couldn’t be studied, the cynical misuse of ersatz legitimacy certainly can be, and is.

The concern, then, isn't that this particular line of research on the psychology of procedural justice shows nothing about substantive justice, justice about outcomes. Instead, the worry is that the research's superficiality - its exclusive focus on the subjective reports of citizens concerning their feelings of being regarded or listened to - makes its findings attractive to corrupt governments whose 
goal is a citizenry that is objectively ignored, ineffective, or excluded from the political process, but feels fairly handled. Not only does a solely psychological conception of procedural justice fail to ratify expectations of dignified treatment, it makes it impossible to identify and name the epistemically crippling effects of policies that shape people's preferences using mechanisms whose operation proceeds beneath the level of conscious scrutiny.

After two centuries of representative government, there is now a battery of science-based methods - available for hire - that can be used to manipulate even a vigilant and informed citizenry. Some argue that we need to be debiased; we need to subscribe to reasoning strategies that we know defang each of the threatened biases. We need these strategies to civilize and correct a mind roiling with biases. Others argue that nothing needs to be done in order to improve individual judgment, because a person's biases cancel each other out. This is the unbuttoned view that judgment is more accurate au natural. Just relax and let the decisions run free. Both sides agree that our ordinary reasoning departs from normative standards on any reasonable conception of what reasoning or judgments are for. What separates the view that our biases cancel each other out from the view that they don't is the weight of evidence.

Just think of the conditions that would have to obtain for the unbuttoned view to be true, and how far we are from knowing that they obtain. In many cases, you would have to believe that unsupervised contact with the world conspires to correct powerful biases that always push cognition in one direction. Consider the most widely studied bias: Overconfidence. For judgments of medium to high difficulty, we are systematically over- rather than under confident; overconfidence operates in one direction. In the availability bias, our judgments always favor easily visualizeable rather than invisible causes. In the hindsight bias, we suppose that the foreseeable event makes the event more predictable rather than less predictable. Some tasks involve all three biases at once. In many cases of hindsight bias, for example, we are overconfident that a past event - a very salient or psychologically accessible 
one, like a plane crash or a product malfunction - was more predictable that it actually was. In order for them to cancel each other out, the biases must operate in opposing directions, and their total force would need to have roughly equal magnitude.

\section{$\underline{\text { Government and Judgment }}$}

Specialist committees in the House of Representatives are not designed to protect us from our own natural imperfections (after all, professional politicians, too, are human, and have all the same natural imperfections). They are designed instead to substitute their judgment for the layperson’s, because they are, or can be, in a better position to make accurate judgment about the promise of science-based policies. The committees have some things that lay citizens don't: the authority to demand information be delivered to them, money and staff resources to explore scientific details, easy access to scientific information through the eager cooperation of the academic world, and the secrecy needed for unobstructed, and thus more efficient, inquiry into any matter the member deems relevant.

Some barriers to effective judgment in government are understandable, like the impulses of troubled citizens who dog and harass political staff. Government offices do not have the staff resources to respond immediately to all inquiries, let alone ones from disturbed individuals. If each person demanded the same amount of time, for informational purposes, from government offices, then the time citizens get during which to be heard is $n / p$, where $p$ is the relatively small number of staff hours available to address public concerns and $n$ is the total number of individuals who want their issues addressed. But, of course, in practice, the amount of time available to the public is not evenly distributed. The voices of many citizens get crowded out by some (perhaps relatively few) people who have nothing but time and anger.

But even when citizens are earnest and well-meaning - surely the normal case - getting their views heard is far more of a struggle than it should be, especially when the opposing view has money 
behind it. Consider the 1992 presidential candidacy of H. Ross Perot, an oil magnate who had amassed a personal fortune so vast he could bankroll his presidential campaign, and get $10 \%$ of the vote. ${ }^{36}$ Millionaires have learned from Perot's example: Don’t shoot first for the presidency. Aim lower, for Senator or Representative. Local campaign audiences are more likely to chalk up some bizarre behavior to local color rather than deep pathology. Linda McMahon, who once pretended to knee a large man in the groin before an arena-sized audience, was prepared to pay tens of millions of her own money, received when she was CEO of the WWE (World Wrestling Entertainment) to run in Connecticut for the U.S. Senate. Meg Whitman campaigned for the position of Governor of California, paying 143 million dollars of her fortune from eBay and firing her undocumented housekeeper. Not exactly the picture of rugged individualism, John Raes ran for Senator of West Virginia and said of his limestone and steel fortune that "I made my money the old-fashioned way — I inherited it." ${ }^{37}$ While each of these candidates lost their bid, their enormous bankrolls would have buried any normal citizen in the race with negative ads, while padding their own campaigns with costly professional advice, print ads, and press preparation.

The current projection is that the two major parties in the 2012 presidential campaigns together will spend at least 2 billion dollars. The factors that bring this money in are largely nonepistemic. They involve some very large companies attempting to bend politicians' votes in the direction of their companies’ interests, or in the interests of private wealth. No one supposes that what is good specifically for Kraft or Boeing or General Electric is good generally for, say, the constituency of the 18th district of PA. At the same time, there is powerful evidence demonstrating that wealthy donors and lobbyists have more than an equal chance of "being heard" by a Congressperson, who must always be hungry and hopeful for campaign funds.

To view the websites of lobbying or “political consulting” firms, you might get the impression that their only function is to represent, and advocate to elected representatives (or their senior staff) for, 
the merits of their clients’ products and services. But this seems to leave out financial ingredients essential to this goal of informational advocacy. Former Senator William Cohen, Republican from Maine, paints a grittier picture:

"I'd like to see the camera just stay outside the Senate chamber where all of the lobbyists wait for the members to walk through. It's walking a gauntlet, and it's obscene. And I think if the American people saw what legislators go through, and have to pass through every day, and see how they're pulled aside the last moment—-that 'You gotta go with us on this issue; don't forget, we supported your campaign’-I think the American public would finally turn against that and say, let's have people who are elected to do the job, let's stop polarizing - in the sense that every extreme position that can be taken by a commentator, then members of Congress respond to that and try to outdo the commentator so they'll get on his or her show, and therefore reinforce their own extreme positions. I think both on the Left or the Right it's happening. It's not just Republicans; it’s happening on the Left as well.”38

The situation won't get better on its own. Recall the oft-quoted but seldom-heeded insight of Upton Sinclair: "It is difficult to get a man to understand something, when his salary depends upon his not understanding it!" ${ }^{39}$ But for our purposes, it is enough to note that lobbying relationships frustrate the goals of the generic epistemic principle; they do not support citizen’s making their decisions in light of the best available evidence.

An Illustration of Law-Making about Science: The House of Representatives Committee on Science, $\underline{\text { Space, and Technology }}$ 
The House of Representatives has a Committee on Science, Space, and Technology, and in the last few years it has considered at least several hundred bills on highly technical topics ranging from biofuels and carbon capture to methamphetamine cleanup and ocean acidification. It is hard to imagine anything less than a Ph.D. in the specific field of the given legislation yielding an adequate understanding and critical analysis of its science. Unfortunately, there are only 23 Ph.D.'s in the House and only 3 of these are on the Committee on Science, Space, and Technology. ${ }^{40}$ Without expert advice in such diverse fields even a smart person is doomed to ignorance.

In the entire House of Representatives, perhaps two or three legislators could tell you the scientific technicalities of why the release of carbon warms the earth's lower atmosphere, or how stem cells could be used to reverse nerve degeneration. This is not a criticism of legislators; it is rather a description of the informational limits on them. And that is also the reason that we need strict rules for Representatives on the House Committee on Science, Space, and Technology: To educate them well enough to understand the basic scientific issues (if not the specific facts), to require that they attend the educational sessions, and to punish them if they don't or if they misrepresent the content of a bill in a public discussion. Their committee membership is not a favor they are doing for us; it is a duty they choose to assume when elected to office.

Yet the Committee on Science, Space, and Technology does not warn, sanction, or otherwise punish those who misrepresent scientific facts when disseminating information about a bill under discussion to the public. So there is no disincentive (other than the personal suffering caused by one's own indecency) to scuttle a piece of Committee legislation assembled by one’s political opponents by misrepresenting its content and inducing fear of its consequences.

Consider the case of Dana Rohrabacher (R- $46^{\text {th }}$ district CA). As a member of the House Committee on Science, Space, and Technology, Representative Rohrabacher will be judged on his defense of good science. So far, he is failing that test badly. In order to advance citizen aims for 
efficient energy use, one bill before Representative Rohrabacher and the House Committee on Science, Space, and Technology, HR 3247, proposes that the Department of Energy (DoE) tap scientific research in judgment and decision-making to explore "social and behavioral factors that influence energy consumption and acceptance and adoption rates of new energy technologies.” As such, it would look at the reasons that people use energy sparingly or abundantly, purchase gas-guzzling SUVs or electric and hybrid automobiles, turn off lights in unoccupied rooms or leave them on, and with that information attempt to help citizens make more energy-efficient decisions for themselves.

In speeches before the Committee and on television, Representative Rohrabacher is misrepresenting the science behind this generation’s most important discovery in policy-making: We want to make better choices, but we are imperfect decision-makers. Willing and able people neglect to sign up for organ donation, fail to enroll in retirement plans, and don’t shop for a cheaper insurance or cell phone service plan, all when we say we want to. These imperfections, documented by three decades of scientific research on decision-making, lead to poor energy choices as well. Even when we want to support alternative energy options, we use incandescent bulbs, we leave lights burning unattended, we buy gas guzzlers, and we resist wind power stations for reasons deaf to our preferences.

Apparently, judgment research has been difficult for Representative Rohrabacher to understand, but remarkably easy for him to talk about. In his role on the House Committee on Science, Space, and Technology, Representative Rohrabacher repeatedly misinformed the public about the content of the HR 3247. One of his favorite charges was that this research involved “psychiatry”, twisting people’s minds toward a pre-determined political preference. Of course, the bill proposes nothing of the sort. Yet, within a month of HR 3247’s burial in a Committee hearing on July 29, 2009, Rohrabacher showed up on Glenn Beck's now-defunct Fox News show (no doubt because he was a member of the Committee) to reassure his Orange County constituents and any uncommitted oil interests that he would not be considering evidence of cleaner alternatives over fossil fuel energy. Regrettably, his 
understanding of HR 3247 displayed in Committee debate was no more sophisticated than that of clean energy:

"Do we want single-family homes to be portrayed as so inefficient that we have to hire psychiatrists to convince people to move into condominiums or apartment complexes, because that's so much more energy efficient?"41

The reference to psychiatry is a dead giveaway that he either rejected the many Committee efforts to educate its members on this topic or misrepresented expert testimony because the science behind the bill would undermine his prejudices. HR 3247 has nothing to do with psychiatry. Instead, it involves the much-celebrated results of basic research in behavioral economics and judgment. It is disturbing that this senior member of the House Committee on Science, Space, and Technology doesn't recognize the difference between the science of decision-making and the profession that treats schizophrenia and manic depression, the difference between cognitive psychology and the medical practice of psychiatry. And even more disturbing if he knows the difference but is distorting the scientific findings. Either way, there is every reason for the House Committee on Science, Space, and Technology to reprimand a member who flouts experts or deliberately utters falsehoods to the media, or any public venue, because in all of these cases national interests are at stake.

Now, this leaves plenty of room to criticize the bill. You might wonder, for example, why the DoE should administer a 50 million dollar research program when the National Science Foundation’s Directorate for the Social, Behavioral and Economic Sciences already has the infrastructure for this research and funds work like it (though this is not Rep. Rohrabacher's misgiving). And if this treatment of Representative Rohrabacher here appears rough, it is not because we learn from studies of political character or take pleasure in from harsh judgments. Indeed, it is not the purpose of this study to blame 
the corrupt practices of individuals. Rather, it is to point to broader aspects of political decision-making that cultivate poor judgments. In fact, the incentives for deception and negligence must be powerful, because Representative Rohrabacher is no lone rogue. While on the Science, Space, and Technology Committee with Rep. Rohrabacher, Mario Diaz-Balart (R-FL, now a member of the Appropriations Committee), too, mines blindly for ridiculous interpretations of the bill's text, asking whether the DoE needs approval of the bill because "American people are not capable of turning on a light, and turning it off? We're not capable of using a towel twice before washing it? So it's the federal government's role to now tell us that?" ${ }^{\text {22 }}$ Whatever one concludes about Rohrabacher and Diaz-Balart's vulnerability to incentives for deception and negligence, the very fact that it is so easy to find two representatives engaged in such blatant misrepresentation indicates the existence of more systematic (often partisan) inducements to misrepresent the resolutions before the House Committee.

Unfortunately, in a classic case of "motivated reasoning”, these fears about government mind control are sheer fantasy. Do Representatives Rohrabacher and Diaz-Balart really think that economists at business schools from Duke and University of Chicago to Northwestern, UCLA and UCSD - where much of this decision science originates - are engaged in a plot to limit citizen freedom and practice psychiatry on them? In fact, HR 3247 does just the opposite. It attempts to identify the options that will allow people to take courses of action they say they want. Why, then, would Representative Rohrabacher want to interfere with effective alternative energy choices? Perhaps Rohrabacher himself answered that question best in 2009 when talking about his colleagues and constituents: "Now I happen to support offshore oil drilling...I'm going to convince them it's in their interest to have oil coming from offshore." ${ }^{43}$ And sadly, just months later with the BP Gulf oil spill, his wish came true for all of us. But for the Department of Energy bill, there is no science behind Rohrabacher's deception, just oil and ideology. The problem is, House rules allow it. 
Members of Congress are not known for sterling conduct, and Congressional rules do not compel high standards. A Congressman can visit a prostitute and get re-elected, or even commit a felony and never leave the fold. As one House document puts it: "Members of Congress do not automatically forfeit their offices upon conviction of a crime that constitutes a felony." ${ }^{44}$ What does it take?

There are broader lessons here about the obsolescence of the Committee on Science, Space, and Technology which, after all, has all the Cold War klunkiness you would expect from a Government Science committee assembled to respond to Sputnik. Yet regardless of the Committee's outdatedness, it is an unfortunate consequence of its members' actions that federal funding for the advancement of knowledge_-even for the most durable mysteries of the universe-faces such trenchant opposition that funding agencies are driven to near-comical efforts at self-promotion. In order to capture public support, NASA has a publicity page that assures us that space research is not a waste of money, stating that the agency's innovations have thrown off indirect, unexpected benefits, like enriched baby food, scratch-resistant lenses, and better golf balls and portable coolers. ${ }^{45}$

It would seem that the very research designed to advance the generic epistemic principle, crucial to realizing an effective democracy, is under attack. ${ }^{46}$ In 2003, then Representative (now Senator) Pat Toomey (R-PA) and former Senator Richard Santorum (R-PA) threatened the scientific integrity of the peer review process by presuming to pass judgment on the method and substance of five peer-reviewed grants funded by the National Institutes of Health (NIH). Toomey introduced an amendment (the “Toomey Amendment”) on the House floor that sought to eliminate their funding. Neither Santorum’s law degree nor Toomey’s MBA trained them to evaluate social science data.

Clearly, we need a more systematic method of controlling incursions into arcane science by political opportunists. Voters need to know how and by whom untutored politicians get advised, and whether they show up for expert panels and educate themselves before deciding on a policy. Citizens 
need evidence that there is a political price to pay for dishonesty; the House should make the misrepresentation of scientific results a sanctionable or otherwise punishable offense. The House Committee on Science, Space, and Technology can be proud of more than just better golf balls and cooler chests. But until the Committee learns how to compel responsible behavior from its members, science will continue to be used cynically by members who want to generate campaign funds and whip up the voting base.

On the assumption that lobbying and expensive campaigns are here to stay, a number of procedures, if implemented, would still satisfy basic accountability conditions. All of these procedures are designed to satisfy the Generic Epistemic Principle, the idea that our procedures should be selectively responsive to the best available evidence:

1. On pain of removal from the Committee, members could be required to answer questions posed by the Committee Chair or other members about the content of the House Resolutions before them. This would insure that they either attended the expert panels, or that they satisfied the Committee that their post-baccalaureate training constituted an expertise relevant to the resolution under consideration. There is a simple rationale for this measure: Committee members must be accountable for ignorance. This standard would apply when Committee members failed to educate themselves about the arcane details of the topics before the Committee, and the expert testimony about it. This failure could come in the form of not attending expert educational panels and talks arranged by Committee staffers. It is possible that they simply don't know that they are making assertions that are false, and so the misrepresentation is not deliberate; it is the result of ignorance. But that is why we need a way of sanctioning or otherwise punishing individuals who make assertions from ignorance. For, because we know that errors are the foreseeable outcome of ignorance, willful ignorance clearly 
leads to willful misrepresentation. If a false presentation was not the result of misrepresentation, then it was the result of an inaccurate understanding of the information that expert panels were designed to redress. Thus, the Committee member in question should not be permitted to vote on the proposal.

2. In order to avoid the appearance of a conflict of interest, a committee member's responsibilities on committee should not be co-mingled with activities or statements associated with re-election. As a result, issues that arise in the committee cannot be used in connection with campaign media appearances. Committee members must be able to prove that, when discussing the House Resolution in public settings, they did not misrepresent its scientific content. Misrepresentation is damaging to constituent interests, and should be reprimanded by the House or otherwise punished. Evidence of misrepresentation would be that a representative has had the issue explained to him or her, or that they have a relevant expertise, and yet they appear in public and make assertions in print about a given Bill that are inconsistent with the Bill.

These, too, may be pie-in-the-sky measures. They may at first seem to threaten administrative nightmares, but other House Committees must abide special rules, such as the Committee on Homeland Security, which prohibits members from discussing the content of bills with the media. And the cost of implementing them must be balanced against the cost of not implementing them, the cost of demonstrable ignorance and undignified illusion of inclusion. If you are going to allow lobbying and untraceable contributions to election campaigns - and only a 24-month waiting period before a House member can become an employee of a lobbying firm - then you should also have to prevent the appearance that your House Committee activities are in the service of re-election. 
Without these outside strategies in place, ${ }^{47}$ it is possible to manipulate the citizenry in media appearances and campaign literature; and as we noted at the outset, epistemic inclusion is motivated by the recognition that institutional manipulation of citizens is incompatible with their dignified treatment. At the same time, we must ask whose responsibility is it to reverse this kabuki theater that modern political participation has become in the United States. What we need are institutions that secure honest behavior from politicians, rather than standards that heap responsibility on citizens who, in order to meet them, must constantly ferret out “correct” information, calculate outcomes, and assess politicians” honesty.

\section{$\underline{\text { Conclusion }}$}

Exorbitant campaign costs and lobbying influences may be small contributors to the unresponsiveness of governments, when compared to the larger facts about governmental structure. The United States is a majoritarian democracy, and at least as far back as Lijphart's magisterial study of 36 countries, we have known that the United States is less responsive to its citizens' preferences than are proportional, consensus democracies. ${ }^{48}$ The superiority of consensus democracies along valued political dimensions is well-documented. Consensus democracies perform better than majoritarian democracies in the protection of minorities, voter turnout, income equality and democratic quality ratings. On a further measure of 'the kindness and gentleness of their public policy orientations', consensus democracies outpace majoritarian systems. Examples include a higher relative share in terms of welfare state provisions, more energy efficiency, more foreign aid to less-developed countries, lower incarceration rates and generally less punitive regimes, as well as higher levels of satisfaction with democracy. On this last score, citizens in the European consensus democracies feel more "listened to" by their government than citizens of the U.S. 
If there are procedures that allow private interests to overtake common interests, there are also cleverly formulated procedures that could reverse this process. Intellectuals in Europe have long been concerned with the distorting influence of ideology on political representation, and with counteracting it. But there, the target has been a kind of technocratic scientism, a vision that includes scientific experts who make decisions for others by force of specialized knowledge. But the account I have given identifies a cause far more damaging to epistemic inclusion: the familiar concentration of money to serve and secure corporate influence, and the campaign and lobbying laws that function to permit it.

There are, of course, plenty of unrealistic proposals aimed at reducing the appearance and reality of corruption. One would be to eliminate lobbying, or control it as governments do in many European countries. Or, the government could enforce a low and transparent limit on campaign funding, and thus remove the incentive that politicians have to cozy up to financial benefactors of their campaign. But in the U.S., these curatives have little hope of receiving support. The correctives I have proposed, while perhaps more sober, may still seem normative excursions into a fantastical vision. But such visions are always designed to propel remedies as far as they can go, even if they will fall short. Policy making and voting procedures in the U.S. have fallen hopelessly short of the ideals of democratic inclusion. And few events show this more clearly than the utter failure of voting and policy decisions in the U.S. to be responsive to the citizenry or selectively sensitive to the best available evidence. 
References

Aitchison, J. 2003. Words in the mind: An introduction to the mental lexicon: 3rd edition. Oxford and New York: Basil Blackwell.

Bishop, M., and Trout, J.D. 2005. Epistemology and the Psychology of Human Judgment. New York: Oxford University Press.

Cartwright, N. 2007. Hunting Causes and Using Them. Cambridge: Cambridge University Press.

Christiano, T. 1996. The Rule of the Many. Boulder, CO: Westview.

Citizens Assembly on Electoral Reform, British Columbia. 2004. Improving democracy in B.C.: The final report. http://www.citizensassembly.bc.ca/public. Retrieved February 26, 2008.

Dahl, R. 1971. Polyarchy: Participation and Opposition. New Haven: Yale University Press.

Dahl, R. 1989. Democracy and its Critics. New Haven: Yale University Press.

Dahl, R. 1998. On Democracy. New Haven: Yale University Press.

Dawes, R. \& Corrigan, B. 1974. Linear models in decision making. Psychological Bulletin, 81(2): 95106. 
Estlund, D. 2003. Why not epistocracy? In N. Reshotko (ed.), Desire, Identity and Existence: Essays in Honour of T,M. Penner. Edmonton: Academic Printing and Publishing.

Estlund, D. 2008. Democratic Authority. Princeton, NJ: Princeton University Press.

Fischhoff, B., \& Eggers, S. (in press). Questions of competence: The duty to inform and the limits to choice. In E. Shafir (ed.), The behavioral foundations of policy. Princeton: Princeton University Press.

Gigerenzer, G. and Hoffrage, U. 1995. How to improve Bayesian reasoning without instruction: Frequency formats. Psychological Review 102(4): 684-704.

Goldman, A. 1999. Knowledge in a Social World. New York: Oxford University Press.

Hume, D. 1739-40; 1978. A Treatise of Human Nature. L.A. Selby-Bigge (ed.). New York: Oxford University Press.

Kahneman, D., Slovic, P. \& Tversky, A. eds. 1982. Judgment Under Uncertainty: Heuristics and Biases. Cambridge: Cambridge University Press.

Kerr, N.L., Davis, J.H., Meek, D., \& Rissman, A.K. 1975. Group position as a function of member attitudes: Choice shift effects from the perspective of social decision scheme theory. Journal of Personality and Social Psychology, 31(3): 574-593.

Kitcher, Philip. 2001. Science, Truth, and Democracy. New York: Oxford University Press. 
Laughlin, P.R. \& Early, P.C. 1982. Social combination models, persuasive arguments theory, social comparison theory, and choice shift. Journal of Personality and Social Psychology, 42(2): 273-280.

Lijphart, A. 1999. Patterns of democracy: Government forms and performance in thirty-six countries. New Haven: Yale University Press.

Lovie, A. D. \& Lovie, P. 1986. The flat maximum effect and linear scoring models for prediction. Journal of Forecasting 5(3): 159-168.

Maskell, J. 2007. Status of a Member of the House Who Has Been Indicted for or Convicted of a Felony. Congressional Research Service. CRS Report for Congress. Washington, D.C.: Congressional Research Service.

Rich, F. The color on McMahon, Whitman, and Raese. New York Times, Sunday Nov 14, 2010.

Sanders, G.S. \& Baron, R.S. 1977. Is social comparison irrelevant for producing choice shifts? Journal of Experimental Social Psychology, 13(4): 303-314.

Sinclair, U. 1994. I, Candidate for Governor: And How I Got Licked. Berkeley; Los Angeles: University of California Press.

Stoner, J. A. F. 1961. A comparison of individual and group decisions involving risk. Unpublished Master's Thesis, Massachusetts Institute of Technology. 
Stoner, J.A.F. 1968. Risky and cautious shifts in group decisions: The influence of widely held values. Journal of Experimental Social Psychology, 4(4): 442-459.

Sunstein, C.R. 2009. Going to Extremes: How Like Minds Unite and Divide. Oxford; New York: Oxford University Press.

Surowieck, J. 2004. The Wisdom of Crowds: Why the Many Are Smarter Than the Few and How Collective Wisdom Shapes Business, Economies, Societies, and Nations. New York: Doubleday.

Talisse, R. 2005. Democracy After Liberalism. London: Routledge.

Tedeschi, J. 1981. Impression Management Theory and Social Psychological Research. New York: Academic Press.

Trout, J.D. 2005. Paternalism and Cognitive Bias. Law and Philosophy 24(4, July), 393-434.

Trout, J.D. 2009. The Empathy Gap: Building Bridges from the Good Life to the Good Society. New York: Viking/Penguin.

Tyler, T. 2000. Social justice: outcome and procedure. International Journal of Psychology, 35(2): 117-125.

Wilson, A.M. 1872. Diderot. Oxford; New York: Oxford University Press. 
${ }^{1}$ I would like to thank Andy Kondrat, Paul Moser, Peter Sanchez, David Schweickart and two referees for Synthese, for their comments and suggestions on an earlier draft of this paper. Parts of this paper were presented at the $13^{\text {th }}$ Annual Philosophy of Social Science Roundtable, in Paris in March of 2011, and I am grateful to the audience there.

${ }^{2}$ Dahl 1989, p.108.

${ }^{3}$ Dahl 1989, p.109.

${ }^{4}$ Dahl 1971, p.104.

${ }^{5}$ Dahl 1998, p.54; my emphasis.

${ }^{6}$ The epistemic notion of responsibility reaches into most traditions of political theory, especially democratic liberal theory. Indeed, much of the impulse behind the public education movement was, and continues to be, the goal of civic participation. But enthusiasm for democracy is easily transformed into a euphoric optimism about democratic decision-making, and this is the focus of my argument. Most of the policy literature presupposes the view from liberal theory that apt choices in a democracy depend on free, easy, and equal access to information. It also argues that this kind of informed participation is crucial to a legitimate government and, feeling that informed participation is important, conferring greater legitimacy on the government. But this responsibility is merely formal if there are cognitive, social, political, or administrative barriers to acquiring information or participating in the process.

${ }^{7}$ For a survey of the results, see Trout 2009, chapter 3.

${ }^{8}$ See Estlund, 2003.

${ }^{9}$ The argument of this paper assumes that contingent facts about the sources of human well-being are empirical, and that empirical knowledge of them is not just relevant, but required, to design the political structures to achieve those ends. I grant that some political philosophers and academic 
epistemologists would officially reject the assumption either that we could have knowledge about the nature of human well-being, or that knowledge of it is empirical.

${ }^{10}$ Some epistemologists might be concerned with the appeal to "the evidence" in this expression of the Generic Epistemic Principle. If so, they should feel free to substitute that phrase with "whatever confers relevant epistemic status (e.g., reliable indication, reliable process, causal proximity, consensus, evidence, etc.).”

${ }^{11}$ There are, of course, traditions of moral epistemology. So the principle that one person sees as a principle of political morality could also be a principle of moral or political epistemology. If we regard humans as part of the natural order, then we can expect that there are moral or political truths about human value that can be discovered and whose pursuit we could then recommend.

12 The brand of applied epistemology known as “Ameliorative Psychology” consists of branches of psychology that formulate normative recommendations for the pursuit of knowledge. They recommend that, when proven superior, we should use actuarial methods or statistical prediction rules, errorcatching methods from the heuristics and biases tradition, and the vast knowledge we now have about the limitations of unstructured, impressionistic, and intuitive judgment, when reasoning about matters of significance, like chronic or terminal illness, proneness to violence or recidivism, likelihood of credit default, and a wide range of other diagnostic activities. Nearly always, these areas of psychology yield reasoning strategies that outperform human intuition or subjective judgment as a way of generating knowledge. With the characteristic flourish of Enlightenment projects, advocates of Ameliorative Psychology announce that the science of psychology will set you free.

${ }^{13}$ Hume 1978, p.xxiii.

14 “Eclecticism”, Encyclopaedia, quoted in Wilson 1972, p.237. 
${ }^{15}$ Notice this is not a knock on the traditional, generic epistemic principle, but rather an observation that decision-making procedures in practical governance and policy-making would be properly chastened by compulsory attention to this very weak constraint on responsible decision-making. ${ }^{16}$ Many industrial European nations have government bodies that overlap with the charges of the U.S. House Committee on Science, Space, and Technology. England has The House of Lords Committee of Science and Technoloy (http://www.parliament.uk/hlscience); France has The Parliamentary Office for Scientific and Technological Assessment (http://www.assemblee-nationale.fr/english/opecst.asp); Sweden has no overall committee for science policy, but convenes 15 parliamentary committees, each with its own resources with which to handle committee-specific scientific issues that arise (http://www.riksdagen.se/templates/R_Page___794.aspx); Denmark has The Ministry of Science, Technology and Development. It is a national umbrella office that oversees and funds many subsidiary committees (for one of its charges, see http://en.vtu.dk/).

${ }^{17}$ In Chapters 6 and 7 of Trout 2009, I offer a number of ameliorative recommendations for better democratic decision-making. A number of other philosophers (Cartwright 2007, Goldman 1999, and Kitcher 2001) have attempted to address the kind of expert knowledge that must be acquired and managed for responsible citizenship (also see Bishop and Trout 2005). Psychologists, too, care deeply about these issues, and have developed serious alternatives to the disappointing, existing, decision structures for policy choice. See, for example, Fischhoff and Eggers (in press).

${ }^{18}$ Kahneman, Slovic, and Tversky 1982.

${ }^{19}$ It is true that the claim that we ought to use frequency formats depend on further normative premises that may not be a proper part of Ameliorative Psychology. We might observe, then, that the recommendation to use frequency formats may be conditional (e.g., "Use frequency formats if you want to live a longer, healthier life”, or that a normative declaration is neither distinctly philosophical 
nor especially controversial, however short it falls from certainty (e.g., A longer, healthier life is better than a shorter, less healthy life.)

${ }^{20}$ Lovie and Lovie 1986.

${ }^{21}$ Trout 2009 discusses many examples of cost savings gleaned from scientifically-crafted decision procedures, such as parole decisions. See especially pp.163-168. For a comprehensive view of the epistemic superiority of SPRs, see Trout 2005.

${ }^{22}$ It is worth noting that, while some political theorists (e.g., Estlund 2008 and Talisse 2005) might find this kind of epistemic principle politically relevant, some proceduralists about political legitimacy (e.g., Christiano 1996) might not.

${ }^{23}$ Tyler 2000 is a good place to start.

${ }^{24}$ Citizens Assembly on Electoral Reform, British Columbia, 2004. .

${ }^{25}$ Quoted in Dawes and Corrigan 1974, p. 105.

${ }^{26}$ Dawes and Corrigan 1974, p. 105.

${ }^{27}$ Stoner 1961. See also Stoner 1968.

${ }^{28}$ Sunstein 2009, pp. 5-12.

${ }^{29}$ Kerr, Davis, Meek \& Rissman, 1975.

30 Tedeschi, 1981.

${ }^{31}$ Laughlin \& Early, 1982; Sanders \& Baron, 1977.

${ }^{32}$ For a nice introduction to the topic of priming, see Aitchison (2003).

${ }^{33}$ By most estimates, 60-70\% of a legislator's life is campaign fundraising, not legislating or informing oneself about proposed legislation.

${ }^{34}$ It is this affront to dignity that prompted critical theorists like Horkheimer, Adorno and Habermas to decry the truth-distorting role of ideology. 
${ }^{35}$ Tyler 2000, p.17.

${ }^{36}$ When I was in Cuba in 1993, I was talking to a conference assistant. As he explained the way the neighborhood voting proceeded in Havana, he explained that it must be different in the U.S., where you could become president by being rich. Though it is not clear whether he was suggesting wealth was a necessary or sufficient condition, it is easy to interpret the claim to mean that if you were wealthy, you could make a credible run at the presidency, and certainly a congressional or senatorial seat. And this was hard to argue with, coming off of a presidential push by Ross Perot, viewed by the vast majority of the electorate as disturbingly unhinged.

${ }^{37}$ Rich, $11 / 14 / 10$.

${ }^{38} \mathrm{http}: / /$ www.charlierose.com/view/interview/11173; minute 14:20 - 15:05

${ }^{39}$ Sinclair 1935; 1994, p. 109.

${ }^{40}$ Reps. Bartlett, Lipinski, and McNerney; the committee also contains 4 MDs.

${ }^{41}$ http://science.edgeboss.net/real/science/scitech09/072909m.smi

${ }^{42}$ Transcribed from Full Committee Markup debate 7/29/09. Accessed and transcribed 5/27/10. http://science.edgeboss.net/real/science/scitech09/072909m.smi

Relevant debate starts at 58:30 in video.

${ }^{43}$ Representative Rohrabacher, July 29, 2009, at the meeting on HR 3247 in the House Committee of Science \& Technology.

${ }^{44}$ Maskell 2007, p.1.

${ }^{45}$ http://www.thespaceplace.com/nasa/spinoffs.html; last accessed September 27, 2010.

${ }^{46}$ Chris Mooney dissects the social-psychological forces behind science-denial, in http://motherjones.com/politics/2011/03/denial-science-chris-mooney

${ }^{47}$ See Chapter 4, in Trout (2009). 
${ }^{48}$ Lijphart 1999. 